\title{
A SOCIEDADE DE RISCO E O DESCARTE DE COMPUTADORES
}

Carlos Rogério dos Santos Carvalho ${ }^{1}$

\begin{abstract}
Resumo
O presente artigo aborda a sociedade de risco e suas mudanças sociais, políticas e econômicas, visando trazer à discussão as questões referentes ao consumismo desenfreado dessa sociedade contemporânea, especialmente no que concerne a equipamentos tecnológicos, mais particularmente os de informática e o consequente descarte dos aparelhos substituídos por essas novas aquisições, dando origem ao chamado "lixo eletrônico". Enfatiza a necessidade de compreensão de que estamos vivenciando a "modernidade da Sociedade Moderna", como diz Zigmunt Bauman; chamada de Sociedade de Risco por Ulrich Beck; e de Sociedade Pós-Moderna, como prefere chamar Jean Baudrillard e outros autores, onde todas as relações humanas, em todos os níveis, se modificam e os acontecimentos que geram essas alterações ocorrem rápidos demais. As instituições e os sistemas tradicionalmente estruturados e sedimentados sofreram rupturas fatais, pois as mudanças sociais, econômicas, ambientais e tecnológicas criaram uma nova sociedade, com novos conceitos, novos paradigmas, novos pensamentos e comportamentos. Na parte tecnológica dessas mudanças, especificamente na área da informática e seus equipamentos, no Brasil, será apresentada a problemática, e se fará abordagens sobre a legislação dos resíduos sólidos, através da Lei 12.305/2010, PNRS e da Constituição Federal/1988. Dentro da temática, trata de ideias práticas de ações simples e factíveis que auxiliariam muito no retardo do descarte dos resíduos sólidos decorrentes dos computadores antigos e suas peças tecnológicas. Com os referenciais teóricos que embasaram este trabalho, aliado a experiência do autor do referido texto, sendo proprietário de uma revenda de informática e assistência técnica, com 16 anos de atuação no segmento, considera ser possível e viável a sustentabilidade na informática, onde deveria haver, para a concretização dessa possibilidade, o envolvimento de todo o ciclo produtivo, desde os fabricantes, passando pelos distribuidores, fornecedores, lojistas e com a inclusão de um consumidor final com consciência ambiental, como parte importante e fundamental desse processo.
\end{abstract}

Palavras-chave: Sociedade de Risco; Computadores; Descarte; Resíduos Sólidos.

\section{INTRODUÇÃO}

Dentre os vários aspectos que caracterizam a nossa sociedade contemporânea estão o alto fluxo de bens e capitais, o aumento populacional dos países em geral, o surgimento de vários tipos de doenças, as graves crises ambientais, a grande evolução das altas tecnologias e o desenvolvimento de várias áreas do conhecimento, como as ciências biológicas, com as manipulações genéticas na vida animal, vegetal e humana.

O sociólogo alemão Ulrich Beck, em sua famosa obra "A Sociedade do Risco: rumo a uma nova modernidade" (2010), alertou sobre as profundas modificações que começavam a surgir na sociedade moderna. Essas modificações estavam ocorrendo em todos os níveis: econômico, político, social, tecnológico, filosófico, ambiental e todas as diversas áreas de atuação da humanidade. O sistema da sociedade anterior, a sociedade industrial, surgida em meados do século XVIII, depois de mais de duzentos anos de

\footnotetext{
${ }^{1}$ Advogado (OAB/RS 82.159), Empresário. Pós-Graduação Especialização em Direito Ambiental pela Universidade Federal de Pelotas - UFPel. Mestrando em Educação e Tecnologia pelo Instituto Federal Sul-Riograndense - IFSul - Campus Pelotas. Instituição: Universidade Federal de Pelotas - UFPel E-mail: crcarvalhoadv@gmail.com
} 
hegemonia, começou a dar sinais de decadência, ocasionando uma ruptura no seio da sociedade moderna, pois fatos importantes estavam surgindo, a partir do início dos anos 1980, que causariam intensas alterações na sociedade como um todo.

Foram vários os acontecimentos importantes surgidos após a década de 1980, dos quais citamos a queda do muro de Berlim, do socialismo, os grandes avanços tecnológicos, o surgimento dos primeiros computadores pessoais, a queda de ditaduras militares em alguns países, inclusive no Brasil, o agravamento dos problemas ambientais, com destaque ao grave acidente na Usina de Chernobyl, depois veio a Guerra do Golfo Pérsico, a Guerra dos Balcãs, começa a surgir, ainda incipiente, a internet como maneira de globalizar as relações sociais e econômicas, começam a ocorrer as mudanças de conceitos éticos, estéticos e morais da sociedade tradicional, atingindo instituições seculares com a família, o casamento e a religião católica.

Toda a base em que estava sedimentada a sociedade moderna foi abalada, causando instabilidade em todos os sentidos, desde os aspectos econômicos e sociais até os aspectos emocionais de envolvimentos nas relações entre os indivíduos. Segundo Ulrich Beck (2010), essa instabilidade é uma das causas que geram situações de risco, fazendo projeções pensando no futuro e não no presente, gerando condições de perigo social que atingem a sociedade de maneira diferenciada, vindo a prejudicar mais os menos poderosos. Porém, também podem atingir aqueles que produzem ou se beneficiam desses riscos, causando o chamado "efeito boomerang" ou "tendência globalizante".

Fazendo referência a aludida obra de Beck, o professor italiano Raffaele De Giorgi (2008), autor do texto "O Risco na Sociedade Contemporânea", aborda, paradoxalmente, o risco como algo a ser medido na relação com a sociedade contemporânea, traçando paralelos com eventos originados por decisões e ações a serem efetivadas no futuro.

A sociedade moderna é a sociedade do risco não no sentido ameaçador e apocalíptico que a moda difundiu. É a sociedade do risco porque somente

essa sociedade criou condições para se construir futuros diferentes, para manter elevada a contingência dos eventos, vale dizer, para manter possibilidade sempre abertas quando, em razão de uma decisão, verificou-se um eventual dano que se queria ter evitado e que uma outra decisão poderia ter evitado (DE GIORGI, 2008, p.44) 
De Giorgi (2008) também diz que a sociedade contemporânea é caracterizada pela instabilidade em vários aspectos como social, cultural, econômico, onde, segundo ele, a comunicação com o futuro passa, basicamente, pelo risco, onde não existem mais a almejada estabilidade futura, a segurança e os sistemas ultrapassados de controle em geral, utilizados em grande escala nos tempos conservadores da sociedade moderna.

Ainda sobre o risco, De Giorgi (2008) fala de uma sociedade contemporânea, em que ele, o risco, é parte integrante do seu modo de ser. É caracterizada pela falta de transparência do acontecer, com uma crescente possibilidade de decisão, onde o perigo é um provável fato danoso futuro que resulta de algo externo, fora do poder de opção do agente. Dessa maneira, é possível se falar em risco quando um dano qualquer for entendido como consequência de uma decisão, seja do agente ou tomada por outro diferente dele.

Assim, essa sociedade contemporânea diminui o perigo, com o auxílio da ciência, da tecnologia e da economia atuais e incrementa o risco. O dano ocasionado por algo externo, com as novas tecnologias, se tornou algo que pode se prever e controlar. $\mathrm{O}$ controle desses riscos exige a concepção de outras formas de viver a democracia e a cidadania, exigindo a participação de todos os indivíduos e a luta diante dos perigos que surgem. Esses perigos, infelizmente, não estão distribuídos igualitariamente, porque uns indivíduos são afetados mais do que outros. É importante a constituição de políticas públicas para equalizar essas diferenças e discrepâncias, para a atenuação dos riscos para todos.

O desafio se torna maior na medida em que aumentam as desigualdades sociais que vemos na atualidade. É importante frisar que entender e gestionar os riscos pode ser, também, uma forma de atenuar essas diferenças, que são cada vez mais maiores na sociedade mundial. Com relação à segurança, os velhos sistemas e os ultrapassados requisitos de estabilização social não operam mais. Acabou a estratificação e, com ela, as antigas formas de segurança e garantias de estabilidade no futuro, rompendo com as estruturas do sistema anterior, considerado ultrapassado.

O sociólogo polonês, Zigmunt Barman (2000), autor da obra "Modernidade Líquida", corrobora com as ideias de Ulrich Beck, no que concerne a Sociedade do Risco, falando na sociedade da modernidade líquida, onde aborda a evolução e a 
III SEMINÁRII ECOLDGIA

POLÍTICA

modernidade da sociedade atual, que caminha e avança rapidamente em vários sentidos. Bauman fala na liquidez ilustrando o fato que os líquidos não têm uma forma exata, ou seja, são fluídos que se moldam de acordo com o recipiente nos quais estão contidos, diferente dos sólidos que são rígidos e precisam sofrer uma tensão de forças para moldar-se a novas formas.

Quando Bauman (2000) fala em "Modernidade Líquida", quer fazer alusão ao amolecimento da sociedade e das suas relações, a liquefação das coisas sólidas, coisas essas que eram as bases da sociedade moderna tradicional e conservadora. Anteriormente, a sociedade sólida ou concreta, era repleta de totalitarismo sendo extremamente rígida e não se adaptando as novas formas que estavam surgindo. Agora, as relações humanas não se configuram no longo prazo, pois a efemeridade é uma das características da nova modernidade, onde acontecem mudanças da desregulamentação e privatização das ações modernizantes. As tarefas que eram voltadas ao coletivo, representada na figura da sociedade, acabam se fragmentando em direção ao individual. A responsabilidade vai recair sobre o individuo o qual tem a opção e a liberdade de escolher o seu caminho que deseja trilhar e o modelo de vida que quer seguir ao invés de se guiar por normas pré-estabelecidas por líderes da sociedade e governantes.

Em sua teoria, Bauman afirma que:

Os fluídos movem-se facilmente. Eles "fluem", "escorrem", "esvaem-se", "respingam", "transbordam", "vazam", "inundam", "borrifam", "pingam", são "filtrados", "destilados"; diferentemente dos sólidos, não são facilmente contidos - contornam certos obstáculos, dissolvem outros e invadem ou inundam seu caminho. (BAUMAN, 2001, p.8).

Fazendo uma analogia com a Sociedade de Risco, de Beck (2010), o pensamento de Bauman (2000) confirma a já citada instabilidade e "fluidez" da sociedade moderna, onde as definições, as situações, as tradições, as relações não são mais enraizadas, sedimentadas, solidificadas. Na Sociedade de Risco, o consumismo exacerbado e inconsequente do homem moderno faz parte de suas principais características, fazendo com que esse ato de comprar sempre e tudo o que puder, ostentando bens e modos de bem viver, faça com que o indivíduo se sinta próximo da "felicidade".

O professor Celso Antônio Pacheco Fiorillo, faz considerações sobre as causas agravantes do lixo urbano, onde se inclui o e-lixo (lixo eletrônico): 
Como sabemos, o lixo urbano constitui um enorme problema para a sociedade. A situação vem sendo determinada, em específico, por dois fatores: aumento de consumo e produção de materiais artificiais. (FIORILLO, 2007, p.206).

Outro autor renomado, o professor Édis Milaré, confirma essa teoria do consumismo extremo, por parte de nossa sociedade de risco, dizendo:

Quase todos os grandes problemas ambientais estão relacionados, direta ou indiretamente, com a apropriação e uso de bens produtos e serviço, suportes da vida e das atividades da nossa sociedade moderna (MILARÉ, 2011, p.96).

Porém, essa aquisição de bens materiais e produtos em geral pelos indivíduos, ocasiona, em muitos casos, a necessidade de se desfazer dos outros materiais antigos para promover a substituição e/ou atualização, gerando sobras e resíduos que muitas vezes vão parar nos lixos. Como citado anteriormente, uma das causas principais dessas mudanças sociais econômicas foi a evolução da tecnologia da informação e comunicação, bem como de seus equipamentos. Assim, o presente artigo visa abordar esse desenvolvimento tecnológico, dentro dessa nova sociedade informacional, considerada a sociedade do risco, destacando especificamente os problemas que os equipamentos de informática podem gerar, em termos ambientais, com o descarte indiscriminado de seus resíduos sólidos, tentando buscar soluções que possam amenizar essa situação de malefício à natureza.

\section{Rápido avanço tecnológico na Sociedade}

Na contemporaneidade, o desenfreado desenvolvimento tecnológico, o aumento da produção de equipamentos eletroeletrônicos e as seguidas atualizações e substituições por aparelhos mais velozes e com mais recursos, fizeram com que a preocupação com o descarte dos resíduos sólidos originados por esses equipamentos se tornasse uma das prioridades na sociedade contemporânea. Esse poderoso mercado de equipamentos de tecnologia, principalmente os de computadores e seus periféricos, está em franco crescimento e vem se ampliando cada vez mais. Ele faz com que, em curtos espaços de tempo, haja o lançamento de novos modelos, cada vez mais rápidos e com as 
mais diversas funções. Por outro lado, oferece os mais diversos riscos e impactos negativos ao meio ambiente, quando do seu descarte.

As consequências ambientais, originadas pelo descarte desses resíduos sólidos, têm sido tema de diversas discussões para a busca de alternativas, tanto no setor público como no privado, visando à criação de políticas públicas de educação, conscientização, mecanismos de ajustes, controles e implementação de ações práticas e eficazes para a proteção ambiental. Dentre outras causas que ocasionam a acumulação do chamado "lixo tecnológico", estão o crescimento econômico das cidades, o aumento da população, o avanço da tecnologia, o consumismo massificado e inconsequente que não pondera sobre a real necessidade da aquisição de novos aparelhos e equipamentos, sendo fortemente estimulado e induzido pelo grande poder de influência do marketing dos grandes fabricantes.

Sobre esse consumismo desenfreado, na sua obra "A Sociedade de Consumo", o escritor e sociólogo francês Jean Baudrillard (1981) fala que, na sociedade moderna e pós-moderna, o ideal de felicidade está associado ao consumo e que essa felicidade necessita ser medida através de significâncias, de objetos que sejam representativos do bem estar. Hoje, dentre outras coisas, é sinônimo de "status social" ter aparelho celular de última geração, computador com configurações top de linha, notebooks, netbooks $e$ tablets com grande velocidade de processamento e visual hi-tech.

\section{Impactos Ambientais}

Os equipamentos eletrônicos, especialmente os de informática, objeto desse artigo, contém materiais que demoram muito tempo para se decompor, como plástico, vidro, metais pesados, extremamente maléficos à saúde humana e ao meio ambiente. São muitos os metais pesados presentes nesses equipamentos, dentre eles: mercúrio, chumbo, cádmio, manganês, níquel. Esses componentes, ao serem descartados de forma incorreta, no lixo comum e, posteriormente, enviados para lixões, contaminam tanto o solo como a água e todos aqueles que utilizam essas fontes serão contaminados pelos detritos, o que poderá provocar sequelas extremamente nocivas. As consequências impactantes geradas pela evolução tecnológica provocam graves riscos ao meio 


III SEMINÁRII ECOLOGIA

PDLÍTICA

E DIREITO NA AMÉRICA LATINA

Com os avanços nessa área e a ambição descomedida por lucros, os grandes fabricantes, através de seu poder econômico, começaram a programar estratégias para aumentar a produção e comercialização de novos equipamentos tecnológicos. Surge, assim, a obsolescência planejada ou programada, que é a condição atribuída a um produto ou serviço que deixa de ser útil, mesmo estando funcional, devido ao lançamento de um produto tecnologicamente mais avançado. Na prática, é um sistema que precipita o descarte prematuro de computadores. O francês Jean Baudrillard, sobre a obsolescência planejada escreve:

Vivemos o tempo dos objetos: quero dizer que existimos segundo o seu ritmo e em conformidade com a sua sucessão permanente. Atualmente somos nós que os vemos nascer, produzir-se e morrer, ao passo que em todas as outras civilizações anteriores eram os objetos, instrumentos ou monumentos perenes, que sobreviviam às gerações humanas. (BAUDRILLARD, 1981, p.15).

A poderosa indústria da tecnologia pretende, e está conseguindo, inserir na mentalidade do usuário, que seu computador é um dispositivo de consumo descartável. Dessa forma, surgem alguns questionamentos: Por que se desfazer de um computador perfeitamente funcional se ele ainda atende às necessidades do seu usuário? Por que a grande indústria dos computadores determina quando os computadores ficam obsoletos?

\section{Software livre nos computadores antigos}

Mesmo que um computador seja considerado antigo, mas com as peças em boas condições de funcionalidade, ele ainda pode ser útil. Para isso, tem que ter instalado um sistema operacional leve e demais programas enxutos, sem exageros de recursos e aceleração gráfica. Ao contrário da ideia explicitada, o objetivo dos grandes fabricantes mundiais de equipamentos de informática, é fazer com que os consumidores comprem computadores novos, com novas versões do sistema operacional hegemônico (Windows) de acordo com o seu "calendário" (entenda-se, obsolescência planejada) previamente determinado. Já o computador que utiliza um software livre com sistema operacional é comandado pelas necessidades funcionais, exigindo menos recursos físicos da máquina, oferecendo uma boa funcionalidade, com as vantagens de baixo custo social, segurança e não obsolescência de peças por um longo tempo. 
Além da instalação de um sistema operacional livre e mais "leve", o usuário pode, também, aumentar a configuração de seu computador, através da instalação de determinadas peças, como memória RAM, processador, disco rígido, fazendo o chamado up grade, que seria uma atualização da estrutura física do computador.

Na prática, um computador com configuração desatualizada e antiga, mas com um software livre como sistema operacional (programa que viabiliza as funções gerais e tarefas do computador) ou com um simples upgrade, poderá reproduzir vídeos, processamento de textos, planilhas, power point, e-mails, acessar redes sociais, navegar na internet, chats, visualizar fotos e várias outras funções úteis para maioria dos usuários que hoje utilizam os computadores.

Obviamente que, na situação acima citada, o usuário não poderá exigir grandes velocidades de processamento e rapidíssimas respostas de informações do computador com a configuração exemplificada, comparativamente a um computador mais atual. O objetivo do exemplo é apenas transmitir a informação de que é perfeitamente possível a utilização do equipamento, dentro de suas limitações técnicas, para muitas finalidades profissionais e domésticas dos usuários em geral.

\section{CONSIDERAÇÕES FINAIS}

Por fim, dentro da Sociedade de Risco Contemporânea, é possível se pensar em uma informática com sustentabilidade. Apesar dos pontos negativos e contrários ao meio ambiente, pode ser viável o binômio tecnologia-sustentabilidade, obedecendo e aceitando algumas limitações. Bastam ações simples, que começam com a educação ambiental e a consciência de agir com racionalidade, fazendo com que a tecnologia seja algo da qual se possa tirar benefícios e usufruir de suas vantagens, porém, não se tornando escravo dela e nem do sistema econômico que a sustenta.

Dessa forma, todos sabem que a tecnologia se desenvolve para facilitar a vida das pessoas, mas é importante que esse crescimento venha acompanhado de conscientização. Não basta fazer investimento em novos produtos, mas é preciso pensar em como reaproveitar e recuperar a energia que está sendo descartada. Infelizmente, no Brasil, ainda não existem políticas efetivas que incentivem as pessoas e as empresas a agirem de forma consciente em relação ao descarte de produtos eletrônicos, mas 


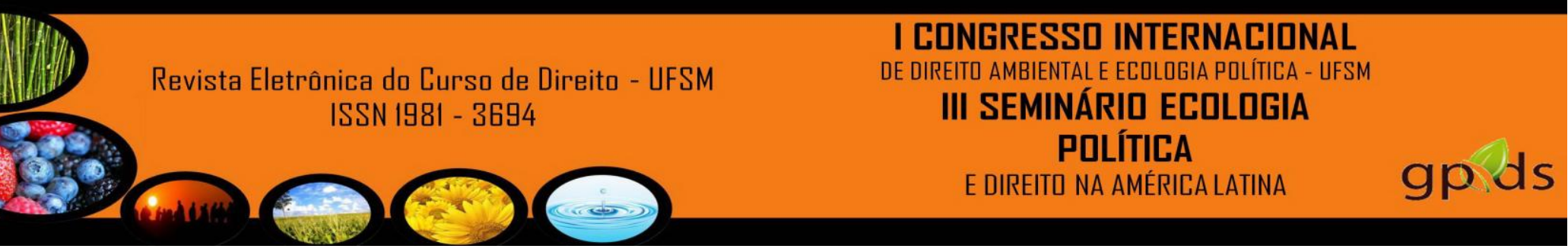

algumas medidas estão aparecendo aos poucos. Vislumbrando um caminho que leve a um sistema sustentável seria o incremento das pesquisas científicas na busca do desenvolvimento de componentes que possam substituir os materiais tóxicos utilizados na fabricação dos equipamentos do e-lixo, fazendo com que esse lixo seja menos tóxico e melhor reciclável no futuro.

Enfim, caminhos existem, ideias surgem, soluções são possíveis. Mas todas essas ideias visando à solução do problema passam pela mudança de consciência e até mesmo de cultura, pois hoje o homem vive em uma sociedade movida pelo desejo de consumo incomensurável. Por isso, a educação e a consciência da população para um consumo mais responsável precisam caminhar juntas e acompanhar esse processo de desenvolvimento social e tecnológico.

\section{REFERÊNCIAS BIBLIOGRÁFICAS}

BAUMAN, Zigmunt. Modernidade Líquida. Rio de Janeiro: Ed. Zahar, 2000.

BECK, Ulrich. Sociedade do Risco: Rumo a uma outra Modernidade, Trad. Nascimento, S., 1ª Edição. São Paulo: Editora 34, 2010.

BRASIL. Constituição da República Federativa do Brasil de 1988. Site do Planalto. Disponível em: 〈http://www.planalto.gov.br/ccivil_03/Constituicao/Constitui\%C3\%A7ao.htm> Acesso em: 27 de agosto de 2012.

BRASIL. Lei $\mathrm{n}^{\circ}$ 12.305, de 02 de agosto de 2010. Institui a Política Nacional de Resíduos Sólidos. Site do Planalto. Disponível em: < http://www.planalto.gov.br/ccivil_03/_ato2007-2010/2010/lei/112305.htm>. Acesso em: 30 de agosto de 2012.

FIORILLO, Celso Antônio Pacheco. Curso de Direito Ambiental Brasileiro. 8. ed. São Paulo: Saraiva, 2007.

GIORGI, Raffaele Di. O Risco na Sociedade Contemporânea, Revista de Direito Sanitário, São Paulo v.9, n.1 p.37-49 Mar/Jun. 2008.

MACHADO, Paulo Affonso L. Direito Ambiental Brasileiro, 19 ed. São Paulo: Editora Malheiros, 2011.

MILARÉ, Édis. Direito do Ambiente: A Gestão Ambiental em Foco, 7 ed. São Paulo: Editora Revista dos Trubunais, 2007. 